\title{
Outcome of donor biliary complications following living donor liver transplantation
}

\author{
Hyun Young $\mathrm{Woo}^{1}$, In Seok Lee ${ }^{2}$, Jae Hyuck Chang ${ }^{2}$, Seung Bae Youn ${ }^{2}$, Si Hyun Bae ${ }^{2}$, Jong Young Choi ${ }^{2}$, \\ Ho Jong Chun 3 , Young Kyoung You ${ }^{4}$, Dong Goo Kim, and Seung Kew Yoon ${ }^{2}$
}

${ }^{1}$ Department of Internal Medicine and Medical Research Institute, Pusan National University Hospital, Busan; Departments of ${ }^{2}$ Internal Medicine, ${ }^{3}$ Radiology, and ${ }^{4}$ Surgery, College of Medicine, The Catholic University of Korea, Seoul, Korea

Received: July 27, 2017

Revised : October 25, 2017

Accepted: November 10, 2017

\section{Correspondence to}

In Seok Lee, M.D.

Division of Gastroenterology, Department of Internal Medicine, College of Medicine, Seoul St. Mary's Hospital, The Catholic University of Korea, 222 Banpo-daero, Seocho-gu, Seoul 06591, Korea

Tel: $+82-2-590-1663$

Fax: +82-2-3481-4025

E-mail: isle@catholic.ac.kr
Background/Aims: Biliary complications are the most common donor complication following living donor liver transplantation (LDLT). The aim of this study is to investigate the long-term outcomes of biliary complications in right lobe adultto-adult LDLT donors, and to evaluate the efficacy of endoscopic treatment of these donors.

Methods: The medical charts of right lobe donors who developed biliary complications between June 2000 and January 2008 were retrospectively reviewed.

Results: Of 337 right lobe donors, 49 developed biliary complications, including 36 diagnosed with biliary leakage and 13 with biliary stricture. Multivariate analysis showed that biliary leakage was associated with the number of right lobe bile duct orifices. Sixteen donors, five with leakage and 11 with strictures, underwent endoscopic retrograde cholangiography (ERC). ERC was clinically successful in treating eight of the 11 strictures, one by balloon dilatation and seven by endobiliary stenting. Of the remained three, two were treated by rescue percutaneous biliary drainage and one by conservative care. Of the five patients with leakage, four were successfully treated using endobiliary stents and one with conservative care. In overall, total 35 improved with conservative treatment. All inserted stents were successfully retrieved after a median 264 days (range, 142 to 502) and there were no recurrences of stricture or leakages during a median follow-up of 10.6 years (range, 8 to 15.2).

Conclusions: All donors with biliary complications were successfully treated non-surgically, with most improving after endoscopic placement of endobiliary stents and none showing recurrence on long term follow-up.

Keywords: Biliary complication; Tissue donors; Cholangiopancreatography, endoscopic retrograde; Liver transplantation

\section{INTRODUCTION}

The first successful adult-to-adult right lobe living donor liver transplantation (LDLT) was performed in Japan in 1994 [1]; since then, this procedure has been widely and increasingly performed. A worldwide shortage of deceased donors has resulted in LDLT becoming a major treatment strategy for end-stage liver diseases, including hepatocellular carcinoma [2-5]. Donor safety is as important as recipient safety and efficacy, resulting in donor ethical issues with regard to this procedure [2$4,6,7]$. The morbidity and mortality rates for liver graft donors have been reported to be about $21 \%$ and $0.2 \%$ to $0.5 \%$, respectively [6]. The most frequent donor com- 
plications following LDLT are biliary complications. Recent studies have reported that $6 \%$ to $9 \%$ of donors experience biliary complications following LDLT [6-9] and that these complications are more common in right lobe than in left lobe donors [10,11]. Although most biliary complications are minor or transient and improve with conservative care, some require endoscopic, percutaneous, or surgical treatment and even long-term hospitalization. To date, however, few reports have assessed biliary complications experienced by right lobe donors after partial liver resection [10-13]. The present study describes the long-term outcomes of biliary complications in right lobe LDLT donors in our center, and the efficacy of endoscopic treatment for these complications.

\section{METHODS}

Between June 2000 and January 2008, 394 liver transplantation procedures were performed at Seoul St. Mary Hospital, South Korea. Of those, 341 were LDLT, with four involving left lobe donors and 337 involving right lobe donors. The baseline characteristics of the 337 right lobe donors are shown in Table 1. Their median age was 30 years (range, 16 to 62 ), and 221 (65.6\%) were male. All donors underwent open hepatectomy. Intraoperative cholangiography of the intrahepatic duct (IHD) showed that 234 (69.4\%) were classified as type I (i.e., the common hepatic duct was formed by fusion of the right and left hepatic ducts, and the right hepatic duct was formed by fusion of the right anterior segmental duct and right posterior segmental duct); 17 (5.0\%) as type II (i.e., the common hepatic duct was formed by the fusion of the right anterior segmental duct, the right posterior segmental duct and left the hepatic duct); 40 (11.9\%) as type III (i.e., the right posterior segmental duct drains into the left hepatic duct); and 46 (13.6\%) as type IV (i.e., the right posterior segmental duct drains into the common hepatic duct) (Fig. 1).

The number of bile duct orifices from the right lobe was defined as the number observed in the stump of the right hepatic duct after right lobe resection. Of the 337 donors, 211 (62.6\%), 117 (34.7\%), seven (2.1\%), and two (o.6\%) had one, two, three, and four orifices, respectively (Table 1).
Table 1. Baseline characteristics of right lobe donors $(\mathbf{n}=337)$

\begin{tabular}{|c|c|}
\hline Characteristic & Value \\
\hline Age, yr & $30(16-62)$ \\
\hline \multicolumn{2}{|l|}{ Sex } \\
\hline Male & $221(65.6)$ \\
\hline Female & $116(34.4)$ \\
\hline Alkaline phosphatase, $\mathrm{U} / \mathrm{L}^{\mathrm{a}}$ & $99(29-310)$ \\
\hline Total bilirubin, mg/dL ${ }^{\mathrm{a}}$ & $0.6(0.12-2.69)$ \\
\hline$\gamma$-GTP, U/L $\mathrm{L}^{\mathrm{a}}$ & $14(4 \cdot 5-140)$ \\
\hline \multicolumn{2}{|c|}{ No. of right lobe bile duct orifices } \\
\hline 1 & $211(62.6)$ \\
\hline 2 & $117(34.7)$ \\
\hline 3 & $7(2.1)$ \\
\hline 4 & $2(0.6)$ \\
\hline \multicolumn{2}{|l|}{ Intrahepatic duct anatomy } \\
\hline Type I & $234(69.4)$ \\
\hline Type II & $17(5)$ \\
\hline Type III & $40(11.9)$ \\
\hline Type IV & $46(13.6)$ \\
\hline No. of blood transfusions ${ }^{b}$ & $2(0-9)$ \\
\hline$\leq 2$ & $185(54.9)$ \\
\hline$>2$ & $152(45 \cdot 1)$ \\
\hline $\mathrm{BMI}, \mathrm{kg} / \mathrm{m}^{2}$ & $23.2(17.09-34.53)$ \\
\hline$\leq 23$ & $156(46.3)$ \\
\hline$>23$ & $181(53 \cdot 7)$ \\
\hline Surgery time, min & $360(300-625)$ \\
\hline$\leq 360$ & $170(50.4)$ \\
\hline$>360$ & $167(49 \cdot 6)$ \\
\hline Weight of left lobe, g & $511(288-1,025)$ \\
\hline$\leq 500$ & $151(44.8)$ \\
\hline$>500$ & $186(55 \cdot 2)$ \\
\hline \multicolumn{2}{|l|}{ Postoperative complication } \\
\hline Total & $92(27.2)$ \\
\hline Grade 1 & $39(11.5)$ \\
\hline Grade 2 & $25(7 \cdot 4)$ \\
\hline Grade 3 & $28(8.3)$ \\
\hline \multicolumn{2}{|l|}{ Biliary complication } \\
\hline Total & $49(14 \cdot 5)$ \\
\hline Bile leakage & $36(10.6)$ \\
\hline Bile stricture & $13(3.8)$ \\
\hline Major (grade 3) & $14(4 \cdot 1)$ \\
\hline Bile leakage & $4(1.1)$ \\
\hline Bile stricture & $10(2.9)$ \\
\hline
\end{tabular}

Values are presented as median (range) or number (\%). $\gamma$-GTP, gamma-glutamyltransferase; BMI, body mass index. ${ }^{\mathrm{a} B e f o r e ~ o p e r a t i o n . ~}$

${ }^{\mathrm{b}}$ During operation. 

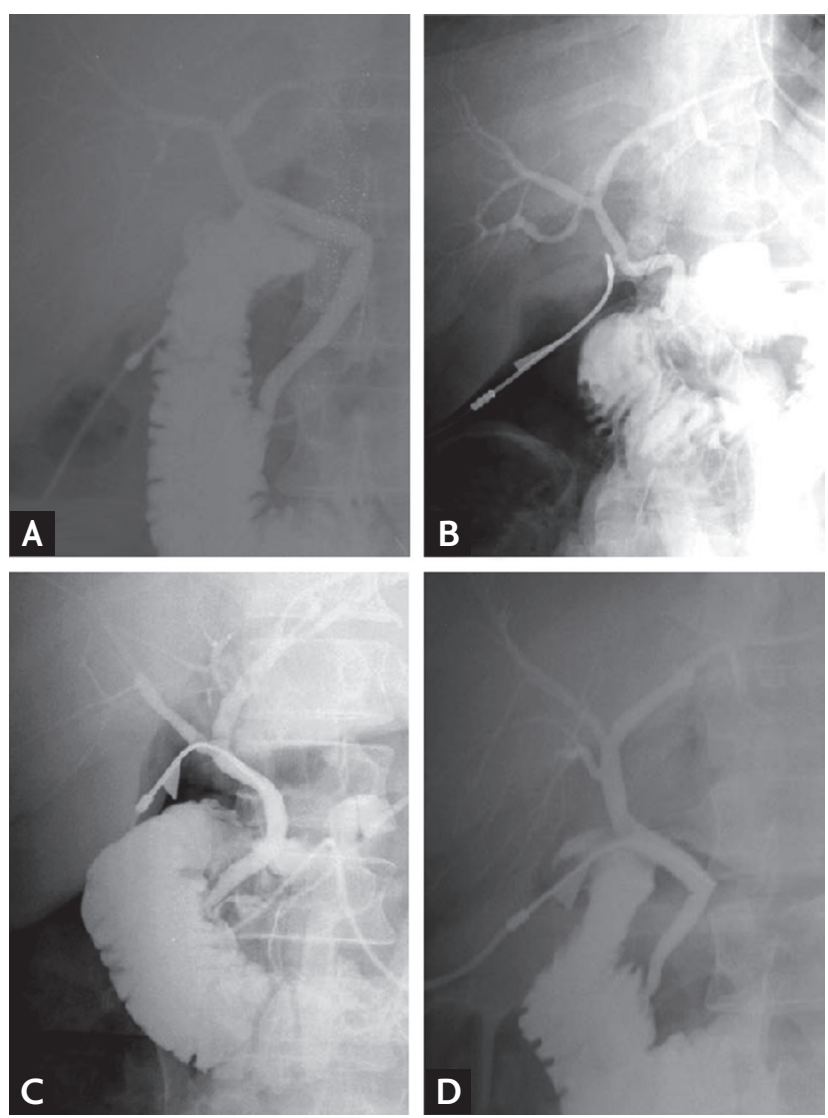

Figure 1. Representative cholangiograms showing variations in the anatomy of the intrahepatic ducts of right lobe donors. (A) Type I, the typical anatomy; (B) type II, triple confluence of the right anterior segmental duct, right posterior segmental duct, and left hepatic duct into the common hepatic duct; (C) type III, drainage of the right posterior segmental duct into the left hepatic duct; (D) type IV, drainage of the right posterior segmental duct into the common hepatic duct.

\section{Definition of biliary complications}

Biliary leakage was diagnosed either when an operatively installed drain contained $\geq 100 \mathrm{~mL} /$ day of bile-containing fluid or when a needle aspirate of intraabdominal fluid included bile juice. If leakage did not resolve following symptomatic care or percutaneous placement of a peritoneal drain, endoscopic retrograde cholangiography (ERC) was performed to confirm the diagnosis and as initial treatment. Biliary stricture was diagnosed when computed tomography or magnetic resonance imaging showed proximal bile duct dilatation and bile duct stenosis, in addition to abnormal liver function test results. The severity of postoperative complications (i.e., biliary complications) was assessed using the five-tier
Clavien-Dindo grading system [14].

\section{Endoscopic procedures}

All endoscopic procedures were performed after written informed consent was provided. After an overnight fast, ERC was performed using a video duodenoscope (Fujinon ED-450XT5, Fujinon, Saitama, Japan). The leakage site was confirmed using contrast media. Following insertion of a 0.035-inch guidewire (Jagwire, Boston Scientific, Boston, MA, USA) into the intrahepatic bile duct proximal to the leakage site, an endobiliary plastic stent was introduced over the leakage site, with or without an endoscopic sphincterotomy (EST). Biliary strictures were dilated using a balloon catheter, or an endobiliary plastic stent was inserted into the bile duct proximal to the stricture site with or without EST. The diameter of the endobiliary stent was based on the lumen size of the donor bile duct. Amsterdam-type biliary stents ( 7 to 11.5 $\mathrm{F}$ in diameter, 10 to $16 \mathrm{~cm}$ in length; Medi-Globe, Achenmuhle, Germany) were used. ERC was again performed 6 months later in an outpatient clinic, or earlier if acute cholangitis or obstructive jaundice developed or the endoscopic retrograde biliary drainage (ERBD) stent was dislodged. During the follow-up ERC, the previous stent was removed and the degree of improvement in biliary leakage was evaluated. The plastic stent was reinserted if the biliary complication remained or recurred after stent retrieval. ERC was considered clinically successful if clinical, laboratory, and radiological abnormalities improved. To confirm the long-term outcome of donors with biliary complication, we checked each donor's status by telephone calls before this study.

This study conformed to the ethical guidelines of the 1975 Declaration of Helsinki, and was approved by our Institutional Review Board (KC17RESIo510). All patients provided informed consent before the treatment.

\section{Statistical analysis}

Descriptive data are expressed as median (range) or proportion. Predictive variables associated with biliary complications were assessed using logistic regression analysis. The evaluated variables were donor sex, age, and body mass index; serum concentrations of aminotransferases, alkaline phosphatase, and total bilirubin; the anatomy of the donor intrahepatic bile duct; the number of bile duct orifices in the right lobe; intraop- 
erative transfusions of packed red blood cells; remnant liver size (left lobe); and the duration of donor surgery. All statistical analyses were performed using SPSS version 13.0 software (SPSS Inc., Chicago, IL, USA).

\section{RESULTS}

Of the 337 right lobe donors, 49 (14.5\%) developed biliary complications. Table 1 shows overall postoperative complication and biliary complication rates according

Table 2. Donor factors associated with the development of biliary complications (leakage or stricture) following liver donation

\begin{tabular}{|c|c|c|c|c|c|c|}
\hline Characteristic & $\begin{array}{l}\text { No } \\
\text { complication }\end{array}$ & $\begin{array}{c}\text { Biliary } \\
\text { stricture }(n=13)\end{array}$ & $p$ value $^{a}$ & $\begin{array}{l}\text { Biliary } \\
\text { leakage }(n=36)\end{array}$ & $p$ value $^{\mathrm{a}}$ & $p$ value $^{\mathrm{b}}$ \\
\hline Age, yr & $30(16-62)$ & $28(18-51)$ & 0.531 & $30(16-53)$ & 0.775 & \\
\hline Sex & & & 0.808 & & 0.564 & \\
\hline Male & $190(66)$ & $9(69.2)$ & & $22(61.1)$ & & \\
\hline Female & $98(34)$ & $4(30.8)$ & & $14(38.9)$ & & \\
\hline Alkaline phosphatase, $\mathrm{U} / \mathrm{L}^{\mathrm{c}}$ & $98.5(29-310)$ & $83(52-160)$ & 0.255 & $112(31-247)$ & 0.861 & \\
\hline Total bilirubin, mg/dL ${ }^{\mathrm{c}}$ & $0.5(0.1-2.7)$ & $0.6(0.12-1.1)$ & 0.756 & $0.6(0.3-1.6)$ & 0.646 & \\
\hline$\gamma$-GTP, U/L ${ }^{c}$ & $14.1\left(4 \cdot 5^{-140}\right)$ & $15(7-28.9)$ & 0.328 & $13.8(6.1-99.0)$ & 0.709 & \\
\hline $\begin{array}{l}\text { No. of right lobe bile duct } \\
\text { orifices }\end{array}$ & & & 0.100 & & 0.008 & 0.010 \\
\hline 1 & $186(64.6)$ & $6(46.2)$ & & $19(52.8)$ & & \\
\hline 2 & $98(34)$ & $6(46.2)$ & & $13(36.1)$ & & \\
\hline 3 & $4(1.4)$ & $1(7 \cdot 7)$ & & $2(5.6)$ & & \\
\hline 4 & o & o & & $2(5.6)$ & & \\
\hline Intrahepatic duct anatomy & & & 0.523 & & 0.043 & 0.601 \\
\hline Type I & $206(71.5)$ & $8(61.5)$ & & $20(55.6)$ & & \\
\hline Type II & $15(5 \cdot 2)$ & o & & $2(5.6)$ & & \\
\hline Type III & $30(10.4)$ & $4(30.8)$ & & $6(16.7)$ & & \\
\hline Type IV & $37(12.8)$ & $1(7 \cdot 7)$ & & $8(22.2)$ & & \\
\hline No. of blood transfusions ${ }^{\mathrm{d}}$ & $2(0-9)$ & $2(0-5)$ & 0.546 & $2(0-4)$ & 0.065 & 0.063 \\
\hline$\leq 2$ & $152(52.8)$ & $8(61.5)$ & & $25(69.4)$ & & \\
\hline$>2$ & $135(46.9)$ & $5(38.5)$ & & $11(30.6)$ & & \\
\hline $\mathrm{BMI}, \mathrm{kg} / \mathrm{m}^{2}$ & $23.1(17-34 \cdot 5)$ & $25.2(20.3-31.1)$ & 0.102 & $23.2(18-27.5)$ & 1.000 & \\
\hline$\leq 23$ & $136(47 \cdot 2)$ & $3(23.1)$ & & $17(47.2)$ & & \\
\hline$>23$ & $152(52.8)$ & $10(76.9)$ & & $19(52.8)$ & & \\
\hline Surgery time, min & $360(300-625)$ & $390(330-570)$ & 0.354 & $390(300-520)$ & 0.410 & \\
\hline$\leq 360$ & $149(51.7)$ & $5(38.5)$ & & $16(44.4)$ & & \\
\hline$>360$ & $139(48.3)$ & $8(61.5)$ & & $20(55.6)$ & & \\
\hline Weight of left lobe, g & $508(255-1,025)$ & $541(405-715)$ & 0.268 & $525(395-669)$ & 0.287 & \\
\hline$\leq 500$ & $134(46.5)$ & $4(30.8)$ & & $13(36.1)$ & & \\
\hline$>500$ & $153(53.1)$ & $9(69.2)$ & & $22(61.1)$ & & \\
\hline
\end{tabular}

Values are presented as median (range) or number (\%).

$\gamma$-GTP, gamma-glutamyltransferase; BMI, body mass index.

${ }^{a} p$ value by univariate analysis.

${ }^{\mathrm{b}} \mathrm{p}$ value by multivariate analysis.

${ }^{\mathrm{c}}$ Before operation.

${ }^{\mathrm{d}}$ During operation. 
to the severity of complications. Biliary complications were the most common postoperative complication (49/92, 53.2\%), with median time to biliary complications being 13 days (range, 1 to 109) after donation. The median age of the 49 donors was 30 years (range, 16 to 53) and $31(63 \%)$ were male. The presenting symptoms and signs were fever $(n=6,12 \%)$, jaundice $(n=11,23 \%)$, collection of intra-abdominal fluid ( $\mathrm{n}=13,28 \%$ ), elevated liver enzymes $(n=16,33 \%)$, and abdominal pain $(n=2,4 \%)$. Of these 49 donors, 36 were diagnosed with biliary leakage and 13 with biliary strictures, including one patient with concomitant biliary leakage.

Univariate analysis of factors potentially associated with biliary complications showed that anatomical IHD type $(p=0.043)$ and the number of bile duct orifices in the donated right lobe $(p=0.008)$ was significantly associated with biliary leakage (Table 2). In contrast, no donor factors were associated with biliary stricture.

Of the donors with IHD types I, II, III and IV, 8.5\% (20/234), $11.8 \%(2 / 17), 15 \%(6 / 40)$, and $17.4 \%$ (8/46), respectively, developed biliary leakage. Moreover, biliary leakage was observed in 9\% (19/211), 11\% (13/117), 28.6\%

Table 3. Clinical outcomes of donors with biliary complications after endoscopic retrograde cholangiography

\begin{tabular}{|c|c|c|c|c|c|c|c|c|c|c|}
\hline No. & $\begin{array}{c}\text { Age, } \\
\text { yr }\end{array}$ & Sex & $\begin{array}{c}\text { No. of } \\
\text { bile duct } \\
\text { orifices }\end{array}$ & $\begin{array}{c}\text { Days } \\
\text { from } \\
\text { LDLT } \\
\text { to ERC }\end{array}$ & $\begin{array}{l}\text { Type of } \\
\text { complica- } \\
\text { tion }\end{array}$ & Type of treatment & $\begin{array}{c}\text { Duration of } \\
\text { endobiliary } \\
\text { stent place- } \\
\text { ment, day }\end{array}$ & $\begin{array}{c}\text { No. of } \\
\text { ERC }\end{array}$ & $\begin{array}{l}\text { Final } \\
\text { state }\end{array}$ & $\begin{array}{l}\text { Follow-up } \\
\text { duration } \\
\text { after stent } \\
\text { removal, yr }\end{array}$ \\
\hline 1 & 28 & Male & 3 & 24 & Stricture & Stent + Rescue PTBD & - & 2 & $\begin{array}{l}\text { Stent and } \\
\text { PTBD } \\
\text { free }\end{array}$ & $15 \cdot 2^{\mathrm{a}}$ \\
\hline
\end{tabular}

$\begin{array}{llll}2 & 51 & \text { Female } & 1 \\ 3 & 41 & \text { Male } & 2 \\ 4 & 41 & \text { Female } & 1 \\ 5 & 40 & \text { Male } & 2\end{array}$

$\begin{array}{lll}47 & \text { Stricture } & \text { Balloon dilatation } \\ 29 & \text { Stricture } & \text { EST }+ \text { Stent }(10 \mathrm{Fr}) \\ 40 & \text { Stricture } & \text { EST }+ \text { Stent }(10 \mathrm{Fr}) \\ 43 & \text { Stricture } & \text { Failed cannulation } \rightarrow\end{array}$

385

Conservative treatment

$\begin{array}{llllll}6 & 38 & \text { Female } & 1 & 42 & \text { Stricture } \\ 7 & 21 & \text { Male } & 2 & 20 & \text { Stricture }\end{array}$

$\mathrm{EST}+$ Stent (10 Fr)

Failed cannulation $\rightarrow$ Rescue PTBD

$\begin{array}{lll}8 & 24 & \text { Male } \\ 9 & 19 & \text { Male } \\ 10 & 21 & \text { Male } \\ 11 & 31 & \text { Male }\end{array}$

$\begin{array}{ll}2 & 38 \\ 1 & 21 \\ 2 & 4\end{array}$

$\begin{array}{ll}38 & \text { Stricture } \\ 21 & \text { Stricture } \\ 41 & \text { Stricture } \\ 43 & \begin{array}{l}\text { Leakage } \\ \text { and }\end{array}\end{array}$

$\mathrm{EST}+\operatorname{Stent}(10 \mathrm{Fr})$

$\mathrm{EST}+$ Stent $(10 \mathrm{Fr})$

$\mathrm{EST}+\operatorname{Stent}(7 \mathrm{Fr} \times 2)^{\mathrm{c}}$

1

-

$2 \quad$ Stent free 11.5

$2 \quad$ Stent free $\quad 11.7$

$1 \quad-\quad 12.3^{b}$

$\begin{array}{ll} & \text { and } \\ & \text { stricture }\end{array}$

$\begin{array}{llll}12 & 26 & \text { Male } & 2 \\ 13 & 21 & \text { Male } & 2 \\ 14 & 26 & \text { Female } & 1 \\ 15 & 23 & \text { Male } & 3 \\ 16 & 37 & \text { Female } & 3\end{array}$

$\begin{array}{ccl}51 & \text { Leakage } & \text { Conservative care } \\ 22 & \text { Leakage } & \text { EST+ Stent }(7 \mathrm{Fr}) \\ 10 & \text { Leakage } & \text { Stent }(7 \mathrm{Fr}) \\ 20 & \text { Leakage } & \text { Stent }(7 \mathrm{Fr}) \\ 7 & \text { Leakage } & \text { Stent }(7 \mathrm{Fr})\end{array}$

245

$\begin{array}{lll}2 & \text { Stent free } & 10.6 \\ 1 & \text { Stent and } & 11.2^{\mathrm{a}} \\ & \text { PTBD } & \\ & \text { free }\end{array}$

\begin{tabular}{cccc} 
& \multicolumn{3}{c}{ free } \\
174 & 2 & Stent free & 10.6 \\
264 & 2 & Stent free & 9.8 \\
142 & 2 & Stent free & 10 \\
202 & 2 & Stent free & 9.4
\end{tabular}

LDLT, living donor liver transplantation; ERC, endoscopic retrograde cholangiography; PTBD, percutaneous transhepatic biliary drainage, EST, endoscopic sphincterotomy.

${ }^{a}$ From removal of PTBD to last follow-up.

${ }^{\mathrm{b}}$ From the day of ERC to last follow-up.

'Two endobiliary stents (7 Fr) were inserted.

${ }^{d}$ Total duration of endobiliary stent placement. 
(2/7), and 100\% (2/2), of the donors with one, two, three, and four biliary orifices, respectively. Anatomical IHD type was significantly associated with the number of bile duct orifices in the right lobe $(p=0.001)$, with multiple biliary orifices more frequently observed in donors with types II (14/17, 82.4\%), III (38/40, 95\%), and IV (45/46, 97.8\%) than type I (29/234, $12.4 \%)$ IHD. Three or more biliary orifices were detected only in donors with types

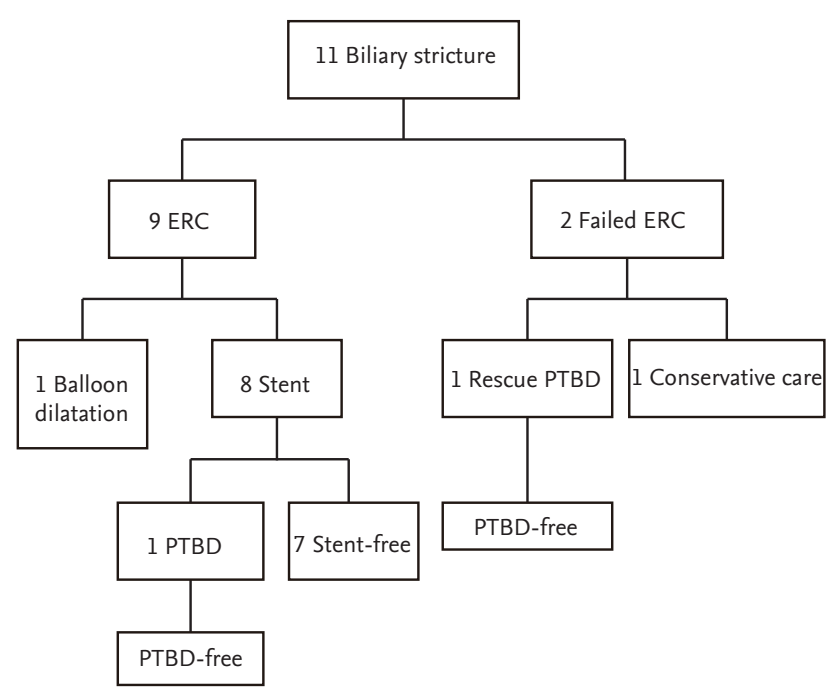

Figure 2. Flow diagram of outcomes in donors who underwent endoscopic retrograde cholangiography (ERC) due to biliary stricture following right lobe donation. PTBD, percutaneous transhepatic biliary drainage.
II (1/17, 5.9\%), III (5/40, 12.5\%), and IV (3/46, 6.5\%). Multivariate analysis found that the number of bile duct orifices was the only factor independently associated with biliary leakage $(p=0.010)$.

Of the 49 donors with biliary complications, 16 donors, including five with leakage and 11 with strictures, underwent ERC; their clinical features and treatment outcomes are shown in Table 3. The median period between LDLT and ERC was 31.5 days (range, 7 to 51). The median number of ERC per donor was 2 (range, 1 to 5 ). None of these patients experienced any serious ERC-related complications, such as pancreatitis, bleeding, or infection.

ERC was technically successful in nine of the 11 donors with biliary strictures, including one with concomitant leakage, but unsuccessful in two patients. Of the latter, one improved without further management and the other underwent percutaneous biliary drainage due to aggravating jaundice. Of the nine donors who underwent technically successful ERC, one underwent balloon dilation alone, whereas the other eight underwent insertion of an endobiliary stent without ballooning, with $(n=7)$ or without $(n=1)$ EST. Of the nine donors with strictures who underwent technically successful ERC procedures, eight experienced successful clinical outcomes, whereas one (Patient 1) required percutaneous biliary drainage because of continuing elevated biliru-
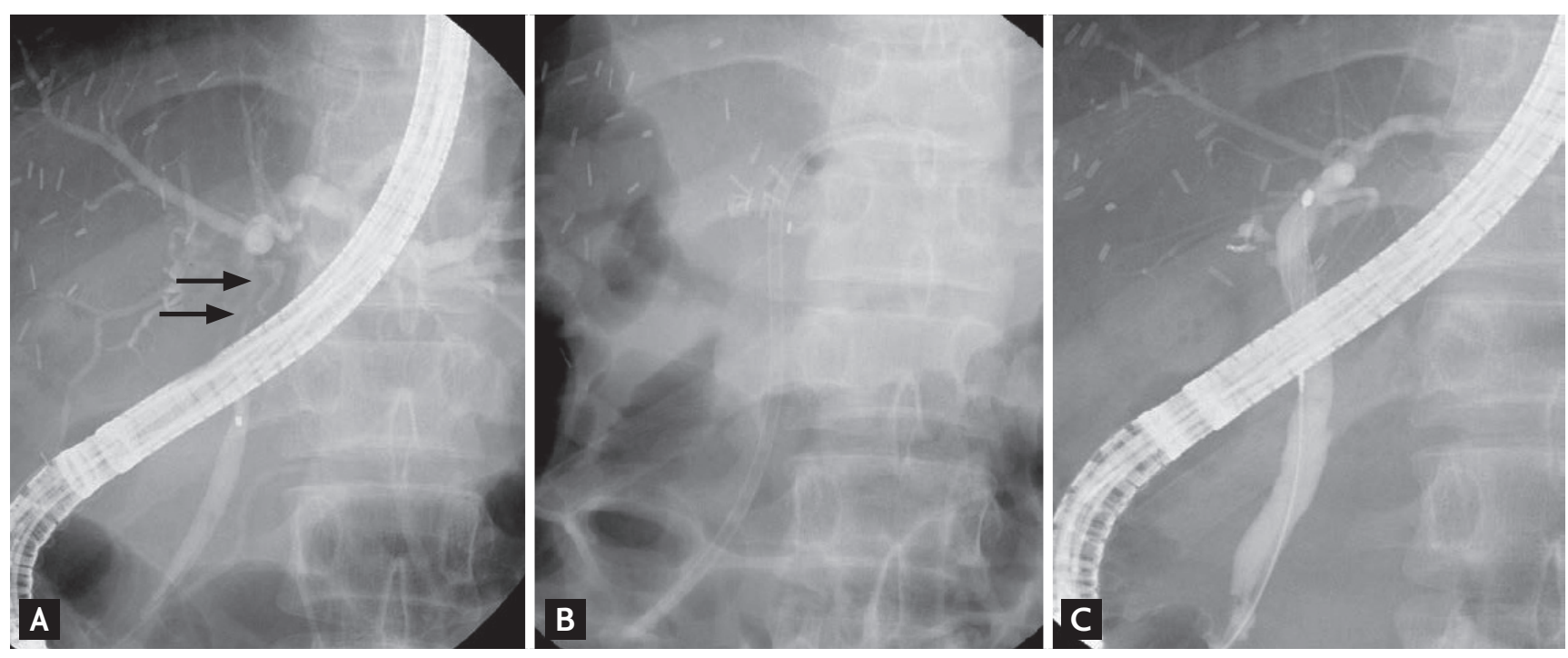

Figure 3. Case of a 19-year-old male donor who presented with biliary stricture (Patient 9). (A) Endoscopic retrograde cholangiography (ERC) showing a common hepatic duct stricture (arrows). (B) Insertion of an endobiliary stent across the stricture. (C) ERC performed 264 days after stenting showing stricture improvement. 
bin concentration and fever (Fig. 2). Drainage was successful in treating fever and jaundice in this patient, allowing drain removal 1 month later. Two weeks later, however, this patient again developed fever and jaundice, and a follow-up ERC showed that the endobiliary stent had migrated towards the smaller intrahepatic bile duct. The stent was removed, with no further recurrence of biliary complications for 15.2 years. Endobiliary stents were removed from the other seven patients removed

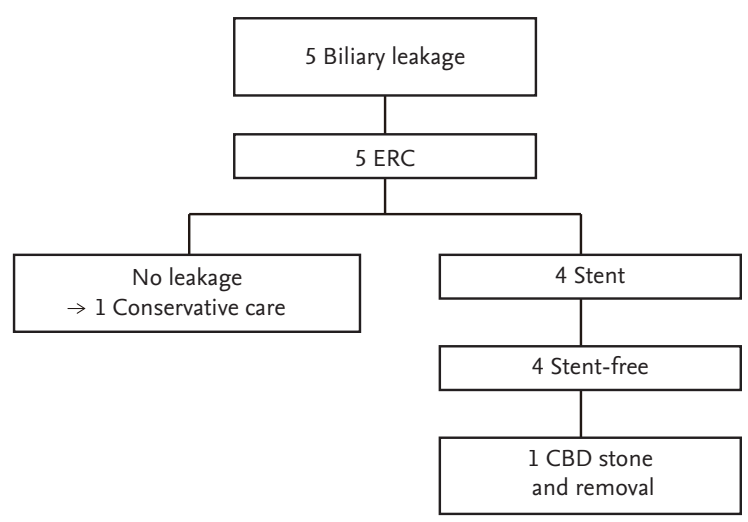

Figure 4. Flow diagram of outcomes in donors who underwent endoscopic retrograde cholangiography (ERC) due to biliary leakage following right lobe donation. CBD, common bile duct. after a median 254 days (range, 142 to 385), with follow-up ERC showing stricture improvement and no evidence of leakage (Fig. 3). None of these patients experienced recurrence of stricture or leakage during a median follow-up of 11.2 years (range, 9.4 to 15.2).

Of the five donors who underwent ERC due to leakage, four underwent endoscopic biliary drainage using a biliary stent. The remaining patient (Patient 12) had a subphrenic biloma and was treated conservatively because bile leakage was not evident on ERC (Fig. 4). The most frequent site of leakage was the anastomosis site of the resected right hepatic duct. The inserted endobiliary stents were retrieved at a median 205 days (range, 148 to 336) following ERC (Fig. 5). Follow-up ERC showed no evidence of leakage in any patient. One patient ( $\mathrm{Pa}-$ tient 13), however, developed obstructive jaundice, with a stone found in the common bile duct 15 days after stent removal. This patient underwent basket stone removal, balloon dilatation of a suspicious biliary stricture, and endobiliary stent reinsertion. The stent was removed 6 months later, with ERC showing no evidence of a stone or stricture in the bile duct. Following stent removal, these five patients with leakage have shown no recurrence of stricture or leakage for a median 8.6 years (range, 8 to 14.2).
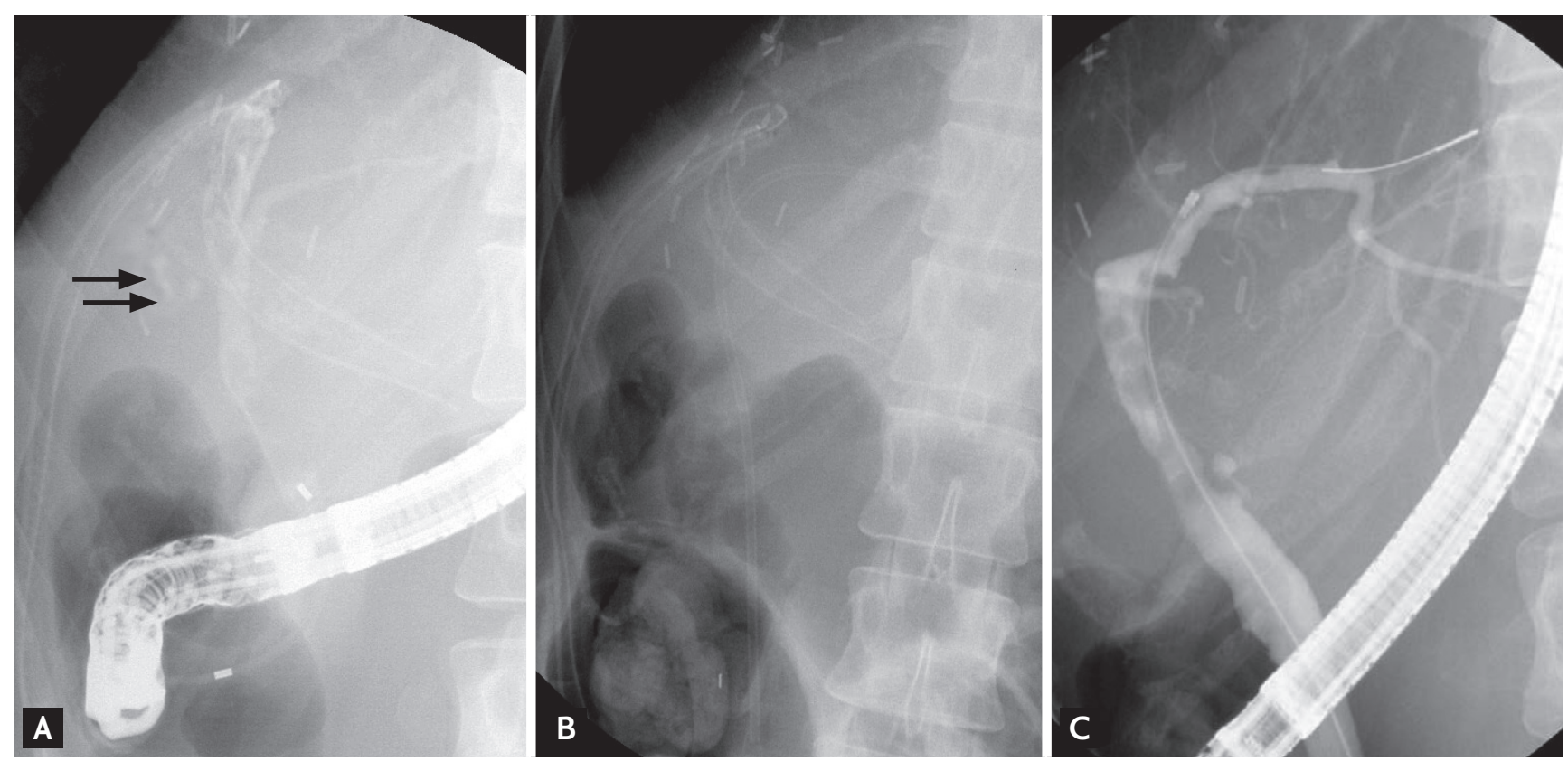

Figure 5. Case of a 26-year-old female donor who presented with bile leakage through the drain (Patient 14). (A) Endoscopic retrograde cholangiography (ERC) showing bile leakage from the resected right hepatic duct (arrow). (B) Insertion of an endobiliary stent over the leakage site. (C) Follow-up ERC showing improvement in biliary leakage and no other complications. 
Thirty-five donors, 32 with leakage and three with strictures, showed improvements following conservative treatment, with none of these patients experiencing recurrence during a median follow-up of 12.8 years (range, 8.9 to 16.3 ).

\section{DISCUSSION}

Although right liver LDLT is regarded as the primary treatment for selected adult patients with end-stage liver disease, concerns have been raised about donor safety. LDLT donors can experience various complications, with biliary complications being the most frequent. However, a multicenter survey of several recent large scale studies showed that donor hepatectomy can be performed successfully, with minimal and easily controlled complications, by using a meticulous and well-standardized technique $[15,16]$. In contrast to largescale studies, single center studies like ours have several advantages. First, specific complications such as biliary complications could be handled in a more detailed and standardized fashion. Second, unexpected intraoperative factors and/or pathologic factors may be identified as important predictors during the investigation. Therefore, this study is one of few focusing on the clinical course of biliary complications and the outcomes of endoscopic management of these complications in LDLT donors at a single center.

The present study found that the overall postoperative complication rate was $27.2 \%$. More than half of these were biliary complications (14.5\%, 49/337), with $10.6 \%$ (36/337) of patients experiencing biliary leakage and 3.9\% (13/337) having biliary strictures, including one donor who developed a stricture after resolution of the leakage. Donor morbidity rates associated with right hepatectomy for LDLT have been reported to range from $0 \%$ to $67 \%$, with an average incidence of $31 \%$ [17]. The overall rate of biliary complications in LDLT donors has been reported to range from $6 \%$ to $9 \%$, but the incidence has been found to vary among studies from 1.0\% to $11.1 \%$ [6-9]. These variations in incidence rate may be due to differences in surgical skills or inconsistent definitions of complications and their grades. The incidence of biliary complications was somewhat higher in the present study than in previous studies. This higher incidence was likely due to our inclusion of only right lobe donors, who have been reported to have a higher rate of biliary complications, about $9 \%$ to $11 \%[10,11]$. However, recent large-scale studies reported comparable outcomes in right lobe and left lobe donors [18-20]. These similar outcomes were likely due to strict donor selection and cumulative experience with surgical procedures and perioperative management [18-20].

We found that most biliary complications occurred during the early postoperative period. Biliary leakage has been found to occur more frequently in earlier than in late phase, with most of these patients showing improvements with conservative care. Biliary strictures develop later, with most requiring specific interventional treatment $[10,21,22]$. In this study, $88.8 \%$ of patients with biliary leakages and $23 \%$ of patients with biliary strictures showed improvement following conservative treatment, findings consistent with those of previous reports $[9,10,12,13,21,22]$. All patients with biliary complications requiring ERC improved without requiring surgical management. ERC was technically successful in 81\% of patients with strictures and $100 \%$ of those with leakage, and endobiliary stent insertion was clinically successful in $72.7 \%$ and $100 \%$, respectively, with the remaining donors responding to percutaneous treatment. Although the management of biliary leakage varies among studies, the approach to stricture is the same, endobiliary stent insertion. The technical and clinical success rates of ERC with stent insertion for stricture in this study were comparable to those of previous studies, although the numbers of events were very small $[10,21,23]$.

In the present study, endobiliary stents were used to treat biliary leakage as well as strictures. Potential treatments for leakage include sphincterotomy, endoscopic nasobiliary drainage (ENBD), endobiliary stent drainage with or without sphincterotomy, percutaneous biliary drainage, and surgery [22,24,25]. Bile leakage after right hepatic duct resection during donor hepatectomy that does not improve with conservative care can be treated initially by endoscopic methods. Endoscopic treatment can reduce the bile duct-duodenal pressure gradient, bridge the defect at the leak site, divert bile away from the leak site, and prevent stricture formation during healing [25]. ENBD can provide visual confirmation of biliary healing using repeat cholangiography and can be easily removed. Therefore, temporary use of ENBD 
is a safe and feasible method of following up leakage in patients with minor biliary leakage during a relatively short admission period. However, potential drawbacks of ENBD include patient discomfort, displacement, and electrolyte imbalance, drawbacks not observed following endobiliary stent insertion. Therefore, because of possible patient discomfort and the need for longer hospitalization, none of the donors in this study underwent ENBD for leakage. Rather, drainage with endobiliary stents was tried in patients who did not improve with conservative care. Biliary leakage is a risk factor for stricture, or is often associated with stricture $[24,26,27]$. Although prior leakage could not be confirmed in most of our patients with stricture, one patient with stricture had concomitant biliary leakage. Endobiliary stent insertion during the initial ERC may be more effective than ENBD for preventing stricture following leakage, as the stent could be maintained in the biliary system for a longer time. Several previous studies of endoscopic management of donor biliary complications reported that biliary leakage was treated with ENBD or ERBD alone, or ENBD followed by endobiliary stent insertion $[10,12,21]$. The optimal strategy for treating patients with biliary leakage has not yet been determined. Moreover, these strategies are difficult to compare because the number of events in each study was very small. Further studies are warranted.

Some patients who failed ERC or did not show improvement with ERC were successfully managed with percutaneous drainage, suggesting that percutaneous transhepatic treatment is effective for treating bile leaks when endoscopic treatments have failed or are contraindicated [28-30]. Furthermore, percutaneous transhepatic biliary drainage (PTBD) was useful for treating long lasting combined complications. These include longterm maintenance of a large-profile catheter (12- to 14Fr) through the percutaneous transhepatic tract during the indwelling period of the PTBD catheter. In contrast, endoscopic treatment requires cannulation of the ampulla of Vater during every procedural session, making the endoscopic approach more time-consuming and difficult.

We also investigated donor factors predictive of biliary complications. Multivariate analysis showed that the number of right lobe biliary orifices was associated with the development of biliary leakage. In addition, the number of biliary orifices was closely associated with IHD anatomy. Right lobe donors have been reported to be more susceptible to leakage than left lobe donors because the biliary tract anatomy is more complex in the right lobe $[7,10,22]$. About half of right-lobe grafts have multiple biliary orifices [22], whereas left-lobe grafts usually have a single orifice. Furthermore, right lobe grafts require resection of the right hepatic duct closer to the bifurcation of the right and left hepatic ducts than do left hepatic ducts in left lobe grafts because the anterior and posterior segmental branches of the right hepatic duct often converge just proximal to the bifurcation $[10,12,22]$. Therefore, right lobe donors with larger biliary stumps due to multiple biliary orifices would be more susceptible to biliary complications, especially leakage, than donors with fewer biliary orifices.

This study had several limitations, including its retrospective design and the relatively small number of patients who underwent ERC due to biliary complications. However, only about 10\% of LDLT donors experience biliary complications, with each case representing a different clinical situation. Moreover, most donors with biliary complications improve with conservative management. Therefore, comparative prospective studies that include all clinical situations would be very difficult to perform. From a practical perspective, the results of this study may provide valuable information about the actual clinical course of biliary complications in liver donors.

In summary, the present study found that all donors with biliary complications were successfully treated using non-surgical management, and that most donors improved with endoscopic endobiliary stent insertion without long-term recurrence. These results suggest that endoscopic methods are useful and effective as a first option for treating right lobe LDLT donors who experience biliary complications that do not improve with conservative management.

\section{KEY MESSAGE}

1. The most frequent donor complications following living donor liver transplantation (LDLT) are biliary complications.

2. All donors with biliary complications were 
successfully treated non-surgically, with most improving after endoscopic placement of endobiliary stents and none showing recurrence on long term follow-up.

3. Endoscopic methods are useful and effective as first options for long-term treatment of right lobe LDLT donors who experience biliary complications that do not improve with conservative care.

\section{Conflict of interest}

No potential conflict of interest relevant to this article was reported.

\section{Acknowledgments}

This research was supported by the Basic Science Research Program through the National Research Foundation of Korea (NRF) funded by the Ministry of Education (NRF-2017R1CiB5015034) and by clinical research grant from Pusan National University Hospital in 2016.

\section{REFERENCES}

1. Yamaoka Y, Washida M, Honda K, et al. Liver transplantation using a right lobe graft from a living related donor. Transplantation 1994;57:1127-1130.

2. Tanaka K, Yamada T. Living donor liver transplantation in Japan and Kyoto University: what can we learn? J Hepatol 2005;42:25-28.

3. Lo CM. Complications and long-term outcome of living liver donors: a survey of 1,508 cases in five Asian centers. Transplantation 2003;75(3 Suppl):S12-S15.

4. Trotter JF, Wachs M, Everson GT, Kam I. Adult-to-adult transplantation of the right hepatic lobe from a living donor. N Engl J Med 2002;346:1074-1082.

5. Trotter JF. Living donor liver transplantation: is the hype over? J Hepatol 2005;42:20-25.

6. Shiffman ML, Brown RS Jr, Olthoff KM, et al. Living donor liver transplantation: summary of a conference at The National Institutes of Health. Liver Transpl 2002;8:174188.

7. Brown RS Jr, Russo MW, Lai M, et al. A survey of liver transplantation from living adult donors in the United States. N Engl J Med 2003;348:818-825.
8. Humar A. Donor and recipient outcomes after adult living donor liver transplantation. Liver Transpl 2003;9(10 Suppl 2):S42-S44.

9. Ghobrial RM, Freise CE, Trotter JF, et al. Donor morbidity after living donation for liver transplantation. Gastroenterology 2008;135:468-476.

10. Shio S, Yazumi S, Ogawa K, et al. Biliary complications in donors for living donor liver transplantation. Am J Gastroenterol 2008;103:1393-1398.

11. Gruttadauria S, Marsh JW, Vizzini GB, et al. Analysis of surgical and perioperative complications in seventy-five right hepatectomies for living donor liver transplantation. World J Gastroenterol 2008;14:3159-3164.

12. Hasegawa K, Yazumi S, Egawa H, et al. Endoscopic management of postoperative biliary complications in donors for living donor liver transplantation. Clin Gastroenterol Hepatol 2003;1:183-188.

13. Fujita S, Kim ID, Uryuhara K, et al. Hepatic grafts from live donors: donor morbidity for 470 cases of live donation. Transpl Int 2000;13:333-339.

14. Dindo D, Demartines N, Clavien PA. Classification of surgical complications: a new proposal with evaluation in a cohort of 6336 patients and results of a survey. Ann Surg 2004;240:205-213.

15. Lauterio A, Di Sandro S, Gruttadauria S, et al. Donor safety in living donor liver donation: an Italian multicenter survey. Liver Transpl 2017;23:184-193.

16. Lee JG, Lee KW, Kwon CHD, et al. Donor safety in living donor liver transplantation: the Korean organ transplantation registry study. Liver Transpl 2017;23:999-1006.

17. Beavers KL, Sandler RS, Shrestha R. Donor morbidity associated with right lobectomy for living donor liver transplantation to adult recipients: a systematic review. Liver Transpl 2002;8:110-117.

18. Iida T, Ogura Y, Oike F, et al. Surgery-related morbidity in living donors for liver transplantation. Transplantation 2010;89:1276-1282.

19. Abecassis MM, Fisher RA, Olthoff KM, et al. Complications of living donor hepatic lobectomy: a comprehensive report. Am J Transplant 2012;12:1208-1217.

20. Uchiyama H, Shirabe K, Nakagawara H, et al. Revisiting the safety of living liver donors by reassessing 441 donor hepatectomies: is a larger hepatectomy complication-prone? Am J Transplant 2014;14:367-374.

21. Yuan Y, Gotoh M. Biliary complications in living liver donors. Surg Today 2010;40:411-417. 
22. Yazumi S, Chiba T. Biliary complications after a rightlobe living donor liver transplantation. J Gastroenterol 2005;40:861-865.

23. Taketomi A, Kayashima H, Soejima Y, et al. Donor risk in adult-to-adult living donor liver transplantation: impact of left lobe graft. Transplantation 2009;87:445-450.

24. Kasahara M, Egawa $\mathrm{H}$, Takada $\mathrm{Y}$, et al. Biliary reconstruction in right lobe living-donor liver transplantation: comparison of different techniques in 321 recipients. Ann Surg 2006;243:559-566.

25. Agarwal N, Sharma BC, Garg S, Kumar R, Sarin SK. Endoscopic management of postoperative bile leaks. Hepatobiliary Pancreat Dis Int 2006;5:273-277.

26. Ostroff JW. Post-transplant biliary problems. Gastrointest
Endosc Clin N Am 2001;11:163-183.

27. Verdonk RC, Buis CI, Porte RJ, et al. Anastomotic biliary strictures after liver transplantation: causes and consequences. Liver Transpl 2006;12:726-735.

28. Hwang S, Lee SG, Sung KB, et al. Long-term incidence, risk factors, and management of biliary complications after adult living donor liver transplantation. Liver Transpl 2006;12:831-838.

29. Amesur NB, Zajko AB. Interventional radiology in liver transplantation. Liver Transpl 2006;12:330-351.

30. Chang JM, Lee JM, Suh KS, et al. Biliary complications in living donor liver transplantation: imaging findings and the roles of interventional procedures. Cardiovasc Intervent Radiol 2005;28:756-767. 